\title{
Cast Syndrome: Single Operator Cholangioscopic View
}

\author{
Angelo Paulo Ferrari* and Fernanda Prata Martins \\ Attending Physician, Endoscopy Unit, Hospital Israelita Albert Einstein, Brazil
}

*Corresponding author: Angelo Paulo Ferrari, Hospital Albert Einstein, São Paulo, Brazil, Rua Dr. Bacelar 317, ap 231, São Paulo SP - Brazil

\section{ARTICLE INFO}

Received: 幽 February 12, 2020

Published: 慧 February 19, 2020

Citation: Angelo Paulo Ferrari, Fernanda Prata Martins. Cast Syndrome: Single Operator Cholangioscopic View. Biomed J Sci \& Tech Res 25(5)-2020. BJSTR. MS.ID.004258.

\section{ABSTRACT}

We present a case report of a young man who developed cast syndrome in the course of endoscopic treatment for post liver transplantation anastomotic stricture, with emphasis on cholangioscopic aspects.

Keywords: Post Liver Transplant Anastomotic Stricture; Cast Syndrome; Cholangioscopy

Abbreviations: LFT's: Liver Function Tests; ERCP: Endoscopic Retrograde Cholangiopancreatography; AST: Aspartate Aminotransferase; ALT: Alanin Aminotransferase; SOC: Single Operator Cholangioscopy; OLT: Orthotopic Liver Transplantation

\section{Case Report}

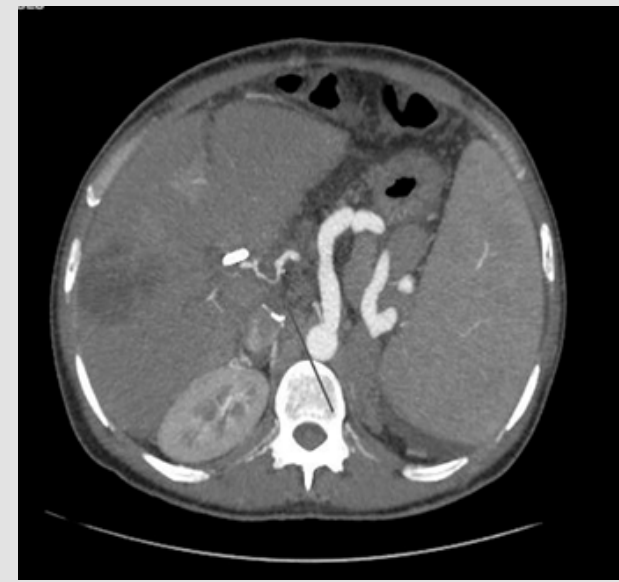

Figure 1: Computed tomography showing hepatic artery stricture (arrow).

This is a 44yo man developed pain with elevated LFT's 20 days after an orthotopic liver transplantation due to viral hepatitis $B$ cirrhosis and was referred to ERCP. At the index ERCP an anastomotic biliary stricture was found, and because of recent surgery (20 days after transplantation), a single $10 \mathrm{Fr}$ plastic stent was placed. He did well for 40 days, and suddenly he developed pain with increased LFT's (alkaline phosphatase/AST/ALT elevated 3 and 15 times over the normal upper limit). Computed tomography disclosed a severe hepatic artery stricture (Figure 1), with intra-hepatic biliary duct dilation. He was again referred to ERCP, plastic stent was removed, and a large biliary dilation with multiple filling defects was noted (Figure 2). Single operator cholangioscopy (Spyglass DS $®$ ) was performed. The anastomotic stricture was large enough to allow easy passage of the cholangioscope and a large dilation with huge amount of junk material was observed, with a characteristic aspect of cast syndrome (Figures 3 \& 4). Debris were removed as much as possible with baskets and extraction balloons. The patient was referred to interventional radiological treatment of the arterial stricture and has been managed clinically. LFT's are still elevated at this point but have dropped to half the initial high values.

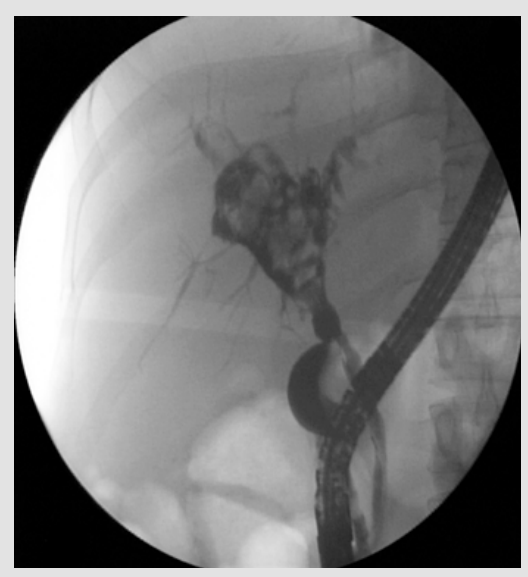

Figure 2: ERCP showing a large biliary duct dilatation, proximal to a anastomotic biliary stricture, with multiple filling defects. 


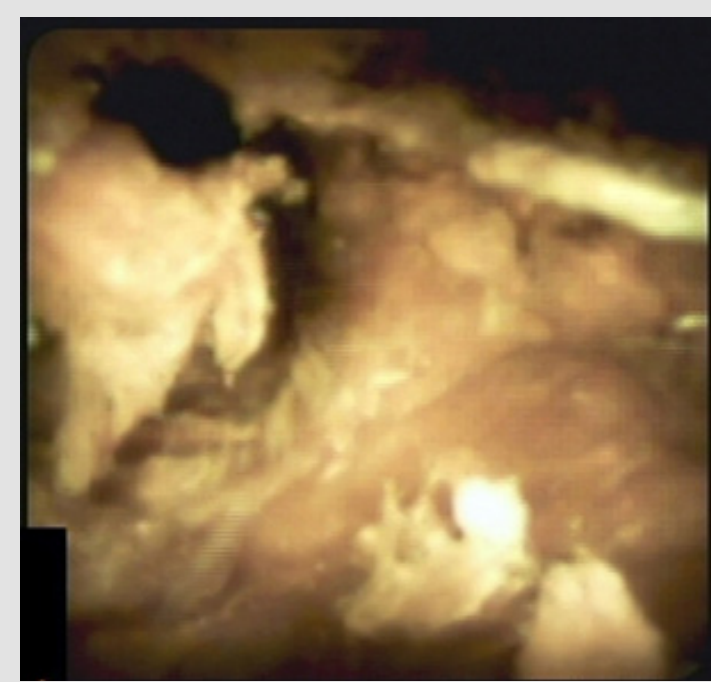

Figure 3: Cholangioscopic view of biliary debris (Cast Syndrome).

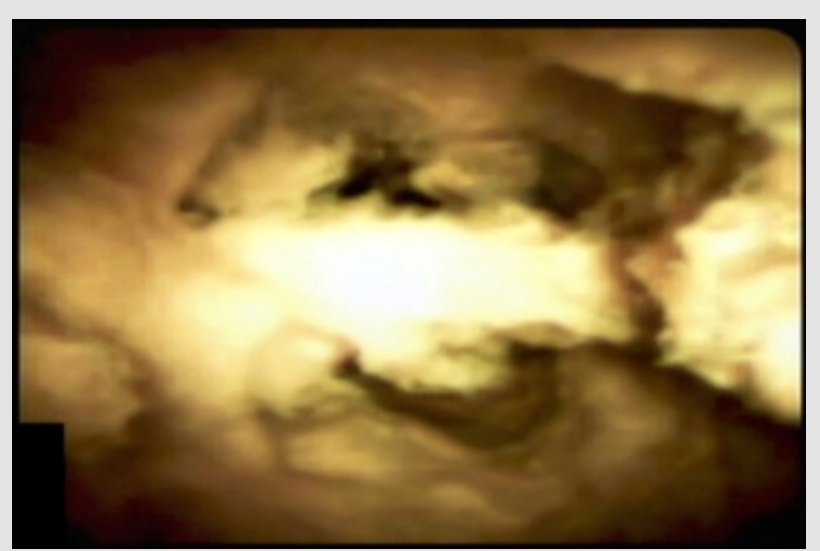

Figure 4: Cholangioscopic view of biliary debris (Cast Syndrome).

\section{ISSN: 2574-1241}

DOI: 10.26717/BJSTR.2020.25.004258

Angelo Paulo Ferrari. Biomed J Sci \& Tech Res

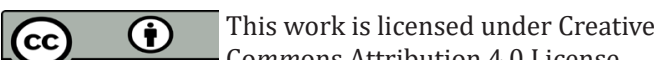

Submission Link: https://biomedres.us/submit-manuscript.php

\section{Discussion}

Biliary cast syndrome incidence after orthoptic liver transplantation can reach up to $18 \%$ of the cases [1]. Ischemic changes are probably determinant in occurrence of biliary complications after OLT [2]. ERCP with exhaustive cleaning of the bile duct is the first therapeutic option [3]. Although it is not essential for definitive diagnosis, cholangioscopy with SOC can visualize both the stricture and debris, leading to a more comprehensive diagnosis and understanding of the actual cause of the obstruction, but has seldom been described in cast syndrome patients [4]. To our best knowledge, our case report is one of very few documentations of SOC in cast syndrome.

\section{Conflict of Interest}

Angelo Ferrari, MD, $\mathrm{PhD}$ is a medical consultant for Olympus and Boston Scientific.

\section{References}

1. Tian H, Liao QD, Li NF, Peng J, Gong LS, et al. (2015) Biliary Cast Syndrome: Hepatic Artery Resistance Index, Pathological Changes, Morphology and Endoscopic Therapy. Chin Med J (Engl) 128(14): 1910-1915.

2. Mourad MM, Algarni A, Liossis C, Bramhall SR (2014) Aetiology and risk factors of ischaemic cholangiopathy after liver transplantation. World J Gastroenterol 20(20): 6159-6169.

3. Mahler MA, Marcaccio F, Dumonceau JM, Macías Gómez C (2017) Successful Endoscopic Management of Late Biliary Cast Syndrome in a Liver Transplant Recipient: A Case Report. Case Rep Gastroenterol 11(1): 207-211.

4. Navaneethan U, Venkatesh PG, Al Mohajer M, Gelrud A (2011) Successful diagnosis and management of biliary cast syndrome in a liver transplant patient using single operator cholangioscopy. JOP 12: 461-463.

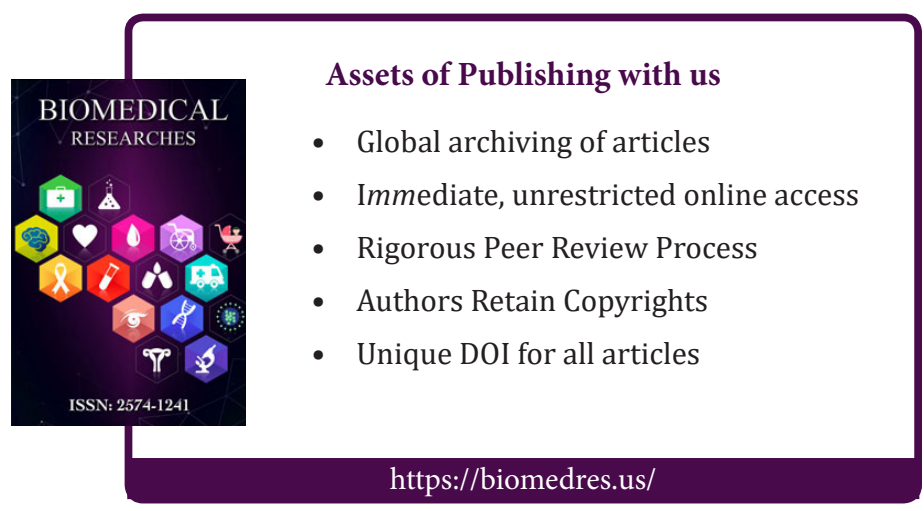

